\title{
Structural Investigations of Solidification and Heat Treatments Influence on High Alloyed Cast Irons Grades with Nb-V-Ti additions
}

\author{
Jacqueline Lecomte-Beckers ${ }^{1, a}$ and Jérôme Tchoufang Tchuindjang ${ }^{1, b}$ \\ ${ }^{1}$ University of Liege, Aerospace \& Mechanics Dpt., Metallurgy \& Materials Science unit - IMGC, \\ Bât. B52 - Chemin des Chevreuils, 1 - 4000 Liege, Belgium \\ aJacqueline.Lecomte@ulg.ac.be, bJ.Tchuindjang@ulg.ac.be
}

Keywords: Cast Iron, Carbides, Graphite, Martensite, Retained Austenite, DTA, Spin Casting Process, Heat Treatments.

\begin{abstract}
Two High Alloyed Cast Irons (HACI) were studied, both belonging to the Fe-C-Cr-Si-X system where $\mathrm{X}$ was represented by $\mathrm{Mo}, \mathrm{Nb}$, Ti or $\mathrm{V}$. One alloy was obtained after adding $\mathrm{Nb}, \mathrm{V}$ and $\mathrm{Ti}$ to the chemical composition of the other alloy.

Raw materials originated from spun cast rolls for hot strip mill were submitted to different heat treatments routes such as double tempering or quenching, in order to study the influence of alloying elements on the microstructure.

Both HACI grades contained a mixture of martensite and retained austenite matrix in the as-cast conditions and after quenching.

Differential Thermal Analysis (DTA) was carried out on the heat treated samples in order to determine the phase transformations occurring during re-melting and subsequent solidification sequence. Retained austenite found in the as-quenched $\mathrm{HACI}$ without $\mathrm{Nb}, \mathrm{V}$ and $\mathrm{Ti}$ additions exhibited an enhanced stability as confirmed by DTA tests.

Various type of martensite were found at the end of heat treatments routes, each having a possible influence on the material behavior while performing re-heating prior to re-austenitisation.

Bulky Nb-rich MC carbides precipitating at the beginning of the solidification process strongly influence the nature and the rate of the subsequent phase transformations, particularly for HACI grade with $\mathrm{Nb}, \mathrm{V}$ and $\mathrm{Ti}$ additions. Such $\mathrm{NbC}$ carbides were also found to segregate during spin casting process.

Quantitative metallography was done to determine graphite, MC carbides, cementite and matrix volume fraction in HACI studied grades.
\end{abstract}

\section{Introduction}

High Alloyed Cast Iron also called Indefinite Chill Cast Irons (ICDP) when used as rolling mill rolls, are cast iron belonging to the Fe-Cr-C-X system, where $\mathrm{X}$ is represented by $\mathrm{Mo}, \mathrm{Nb}, \mathrm{V}$, Ti or even W. X is also known as a strong carbide forming element [1-7]. Precipitation at the same time of free graphite and carbides during the casting process leads to the so called "IC" specific designation. ICDP exhibit improved properties regarding hot oxidation and wear resistances as their microstructure is a mixture of a martensitic with bulky cementite $\left(\mathrm{M}_{3} \mathrm{C}\right)$ and lamellar graphite fully dispersed into the matrix [3, 5, 6]. Mechanical properties involved in HACI depend either on the chemical composition of the alloy or on the crystallization behavior and the heat treatments performed subsequently in order to lead to the desired microstructure [2, 3, 6-9].

Retained Austenite (RA) always present in HACI microstructure at the end of casting process is of concern regarding applications such as hot rolling mill, as this austenitic phase is well-known to be unstable during possible rolling incidents on rolls $[3,4,8,10]$. 
Both martensite and bainite are the defined matrix phases that are sought for working rolls of hot strip mill (HSM) process.

Subsequent heat treatments such as tempering with or without a preliminary quenching, are performed at the end of casting procedure in order to allow a fully transformation of RA into an expected and advisable martensite or bainite matrix [1, 2, 8-15].

Because HSM involved wear and hot corrosion resistances, the microstructure advisable for HACI is composed of a mixture of martensite and cementite, with a certain amount of graphite and other carbides known as eutectic $\mathrm{MC}$ or $\mathrm{M}_{7} \mathrm{C}_{3}$, and fine secondary carbides $\left(\mathrm{M}_{4} \mathrm{C}_{3}\right.$ or $\left.\mathrm{M}_{23} \mathrm{C}_{6}\right)$, the latter carbides being fully distributed inside the material to improve its hardness $[1,3,5,11,15]$. Graphite helps achievement of lubrication during rolling process $[5,14,16]$, while MC eutectic carbides are advisable for wear resistance, as they exhibit a higher hardness [1]. Graphite morphology can vary from flaky to spheroidal type depending on several parameters, each type having an influence on subsequent mechanical properties of the cast iron alloy $[1,7,14,17]$. Indeed rare earth elements and cooling rates were reported to strongly influence the type of graphite that precipitated during the solidification process $[5,18,19]$.

But particular attention must be observed if MC eutectic carbides precipitation is to be promoted in HACI. Indeed it is not recommended that a high hardness difference exists between the matrix and the strengthening particles embedded inside the matrix. Such a high hardness gradient could cause a related differentiated wear on the working roll, with the degradation of the rolling products surface as a consequence $[5,6]$. Then the purpose is either to enhance bulk hardness of HACI by promoting hard MC precipitation, or to insure that such carbides are small in size and uniformly distributed inside the matrix in order to limit the possible differential degradation of the roll.

Controlling the size of carbides, especially eutectic carbides originated from the liquid at the beginning of the solidification process, remain of concern, as many parameter are involved is such a phenomenon. In fact, the chemical composition of the alloy, the casting route and even the subsequent heat treatments can strongly influence the carbides nature, size and distribution inside the matrix $[1-6,19,20]$.

In this work, two grades of HACI had been studied, one grade being obtained after adding $\mathrm{Nb}, \mathrm{V}$ and Ti to the other grade. The stability of RA was enhanced through heat treatments performed on the as-cast samples in order to promote martensite transformation. The study had been focused on the microstructure characterization with the help of DTA, light microscopy, and Image analysis.

DTA is a technique intended to help casting route simulation as heating or cooling modes can be performed at a controlled rate. [1, 3, 6, 8, 18-21]. DTA tests help the determination of crystallization behavior of each alloy, together with the enhancement of phase transformations that occurred during the re-heating process, up to the complete remelting of the materials. Optical microscopy linked to Image analysis makes it possible to determine the phase volume fractions of the heat treated materials.

\section{Materials and Methods}

Studied materials were cut out of the shell part of bimetallic rolls originated from vertical spin casting route. The shell material which is composed of HACI grade represents the barrel whereas the core is formed by a conventional spheroidal grey cast iron. Only the shell materials are involved in this work. 
Average chemical compositions of studied HACI1 and HACI2 materials are given in Table 1. HACI1 represents the "conventional" ICDP grade, whereas HACI2 contains Nb, Ti and V additions.

Table 1: Average chemical compositions of HACI studied grades, -wt\%

\begin{tabular}{|c|c|c|c|c|c|c|c|c|c|c|}
\hline & $\mathbf{C}$ & $\mathbf{S i}$ & $\mathbf{N i}$ & $\mathbf{C r}$ & $\mathbf{M n}$ & $\mathbf{M o}$ & $\mathbf{N b}$ & $\mathbf{V}$ & $\mathbf{T i}$ & $\mathbf{F e}$ \\
\hline HACI & 3.0 & 1.5 & 3.5 & 1.5 & 0.5 & 0.2 & & & & \\
$\mathbf{1}$ & - & - & - & - & - & - & - & - & - & Bal. \\
& 4.0 & 1.5 & 5.0 & 2.5 & 1.5 & 0.8 & & & & \\
\hline \multirow{2}{*}{ HACI } & 3.0 & 1.5 & 3.5 & 1.5 & 0.5 & 1.0 & 1.0 & 0.5 & 0.1 & \\
$\mathbf{2}$ & - & - & - & - & - & - & - & - & - & Bal. \\
\hline
\end{tabular}

Experimental methods laid on heat treatments, solidification and phase transformations study, microstructure characterization, and quantitative metallography.

Heat treatments were done on the specimens, prior to sampling for either metallographic analysis or DTA tests. The heat treatments performed just after the casting process, were either a quenching route or a double tempering stage. The purpose of the thermal treatment was the enhancement of RA stability and the achievement of a fully martensitic matrix, respectively for quenching and for tempering processes. Heat treatment sequences are given in Table 2.

Table 2: Enhancement of origin and heat treatments routes on studied samples, and related analysis types achieved

\begin{tabular}{|c|c|c|c|c|}
\hline $\begin{array}{c}\text { Sample } \\
\text { code }\end{array}$ & Origin & Heat treatment sequence & $\begin{array}{l}\text { Location on } \\
\text { the cast roll }\end{array}$ & $\begin{array}{c}\text { Type of } \\
\text { Analysis }\end{array}$ \\
\hline IC11 & \multirow{3}{*}{ HACI1 } & $\begin{array}{l}\text { As-cast }+ \text { Double tempering } \\
\left(525^{\circ} \mathrm{C} / 24 \mathrm{~h} \mathrm{x} 2\right)\end{array}$ & \multirow{3}{*}{$\begin{array}{l}\text { Between } 20 \\
\text { and } 40 \mathrm{~mm} \\
\text { deep (shell) }\end{array}$} & $\begin{array}{l}\text { Quantitative } \\
\text { metallography }\end{array}$ \\
\hline IC12 & & $\begin{array}{l}\text { As-cast + Double tempering } \\
\left(525^{\circ} \mathrm{C} / 24 \mathrm{~h} \times 2\right)\end{array}$ & & DTA \\
\hline IC13 & & $\begin{array}{l}\mathrm{IC} 12+\text { Austenitizing }\left(815^{\circ} \mathrm{C} / 1 \mathrm{~h}\right) \\
+ \text { Quenching }\left(1000^{\circ} \mathrm{C} / 1 \mathrm{~h} / \mathrm{Oil}\right)\end{array}$ & & DTA \\
\hline $\begin{array}{l}\text { IC21 } \\
\text { IC22 } \\
\end{array}$ & \multirow{3}{*}{ HACI2 } & $\begin{array}{c}\text { As-cast + Double tempering } \\
\left(525^{\circ} \mathrm{C} / 24 \mathrm{~h} \times 2\right)\end{array}$ & \multirow{3}{*}{$\begin{array}{l}\text { Between } 15 \\
\text { and } 40 \mathrm{~mm} \\
\text { deep (shell) }\end{array}$} & $\begin{array}{l}\text { Quantitative } \\
\text { metallography }\end{array}$ \\
\hline IC24 & & $\begin{array}{l}\text { As-cast + Double tempering } \\
\left(525^{\circ} \mathrm{C} / 24 \mathrm{~h} \mathrm{x} 2\right)\end{array}$ & & DTA \\
\hline IC25 & & $\begin{array}{l}\text { IC24 + Austenitizing }\left(815^{\circ} \mathrm{C} / 1 \mathrm{~h}\right) \\
+ \text { Quenching }\left(1000^{\circ} \mathrm{C} / 1 \mathrm{~h} / \mathrm{Oil}\right)\end{array}$ & & DTA \\
\hline
\end{tabular}

DTA tests were done on heat treated specimens in order to determine the solid state transformation and the re-melting behavior of the studied materials.

Furthermore, DTA allowed the enhancement of the crystallization behavior of studied samples.

DTA tests were performed on a Nestchz STA 449 device. The samples were heated and cooled in argon at a rate of $10^{\circ} \mathrm{C} / \mathrm{min}$ for a primary stage that took place entirely in the solid state (up to $1100^{\circ} \mathrm{C}$ ), then a slower heating rate of $5^{\circ} \mathrm{C} / \mathrm{min}$ was used up to the complete melting.

Specimens of heat treated materials and re-solidified materials after DTA tests were polished and etched in order to be examined under optical and scanning electron microscope. Indeed both shape and phase compositions were investigated by means of SEM/EDX analysis. 
Optical characterization of specimens was the preliminary stage before the achievement of the carbides volume fractions assessment towards image analysis.

\section{Results}

DTA diagrams are illustrated on fig. 1 (heating mode) and fig. 2 (cooling mode). Table 3 and Table 4 give the phase transformations which are respectively related to peaks found during the heating and the cooling modes. Fig.3 and fig.4 illustrate the microstructure of re-solidified samples at the end of DTA route, respectively for IC1 and IC2 series.

\section{Phases transformations during DTA heating mode}

From Fig. 1a, as-quenched specimens of HACI1 grade did not exhibited a range for reaustenitisation during the DTA heating mode (lack of peak 3' on IC13), contrary to the double tempered specimen (occurrence of peak $3^{\prime}$ on IC12).

At the same time, an endothermic peak (peak 2') was found on both the as-quenched IC13 sample and the double tempered IC12 sample during DTA heating mode (Fig. 1a), before the austenitisation range.

Thus RA appeared to be stabilized after quenching heat treatment for both IC alloys $[12,13]$.

IC2 series (fig. 1b) show similar behavior contrary to IC1 series, as both double-tempered and asquenched specimens exhibited similar peaks while re-heating them, especially phase transformations that took place before austenitisation (peak 1').and at the time of austenitisation (peaks 3' and 4').

Peak 4' occurrence, only on IC24 double tempered specimen, involved dissolution of fine secondary carbides inside de austenitic matrix. Such carbides were neither found in the as-quenched IC25 sample nor in the IC1 series. Such an observation is consistent with the fact that quenching did not allow fine secondary carbides precipitation contrary to tempering [1].

Above $1000^{\circ} \mathrm{C}$, we observed the reactions that involved re-melting sequence, such as reverse eutectic transformations related to direct melting of both MC carbides (peak 5') or ledeburite (Cementite/austenite eutectic, peak 6'), or up to direct re-melting of graphite (peaks 7' and 8').

Reverse eutectic reaction that involved ledeburite melting (peak 6') appeared to be hardly influence by the previous heat treatments done on the samples for both IC1 and IC 2 series. In fact, double tempered specimens such as quenched specimens of IC1 and IC2 series exhibited similar ranges for reverse eutectic reactions.

Furthermore, the lack of secondary carbides in the tempered IC12 suggested that alloying elements involved in secondary hardening process are no longer present inside the as-cast matrix. Indeed, IC1 series did not contain $\mathrm{V}$, which is well-known to improve secondary hardening during tempering heat treatment.

Although Mo is also a great secondary hardening enhancer, we must assume that most of the Mo containing element was already dissolve inside eutectic carbides for IC1 series.

The melting temperature was obtained around $1260^{\circ} \mathrm{C}$ on IC1 series whereas the same temperature was set at $1245^{\circ} \mathrm{C}$ on IC2 series. Thus $\mathrm{Nb}$, Ti and $\mathrm{V}$ additions appeared to lower the melting point of HACI.

Quenching seemed to enhance RA stability on both IC1 and IC2 series, as the related peak 3' involving austenitisation during DTA heating mode exhibited a reduced amplitude, when compared to that of the double tempered specimens. 
Fig. 1a: DTA curves on IC12 and IC13 (Heating mode at $10^{\circ} \mathrm{C}$ from Room $\mathrm{T}^{\circ}$ to $1000^{\circ} \mathrm{C}$, and at $5^{\circ} \mathrm{C} / \mathrm{min}$ above and up to complete melting

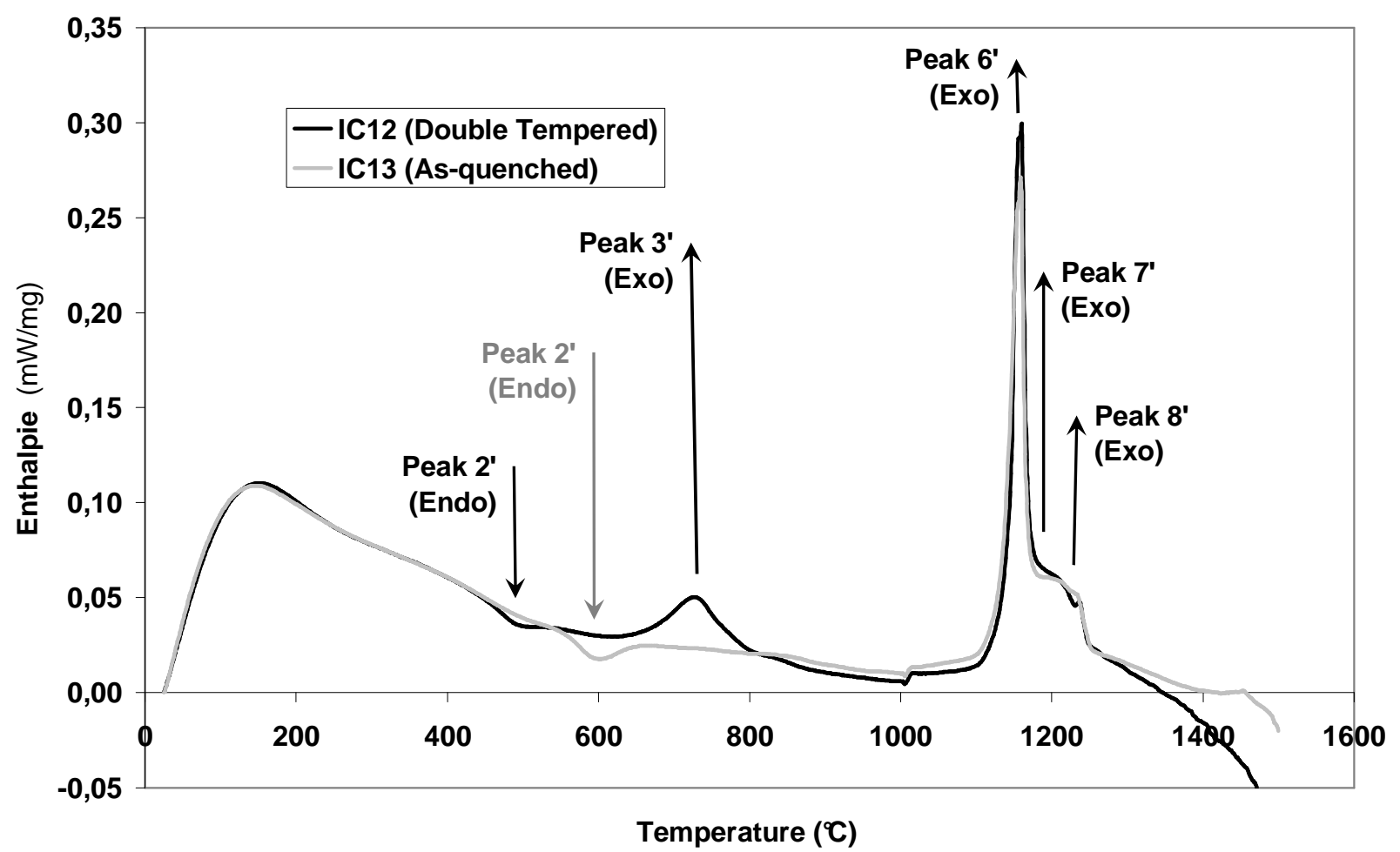

Fig. 1b: DTA curves on IC24 and IC25 (Heating mode at $10^{\circ} \mathrm{C}$ from Room $\mathrm{T}^{\circ}$ to $1000^{\circ} \mathrm{C}$, and at $5^{\circ} \mathrm{C} / \mathrm{min}$ above and up to complete melting

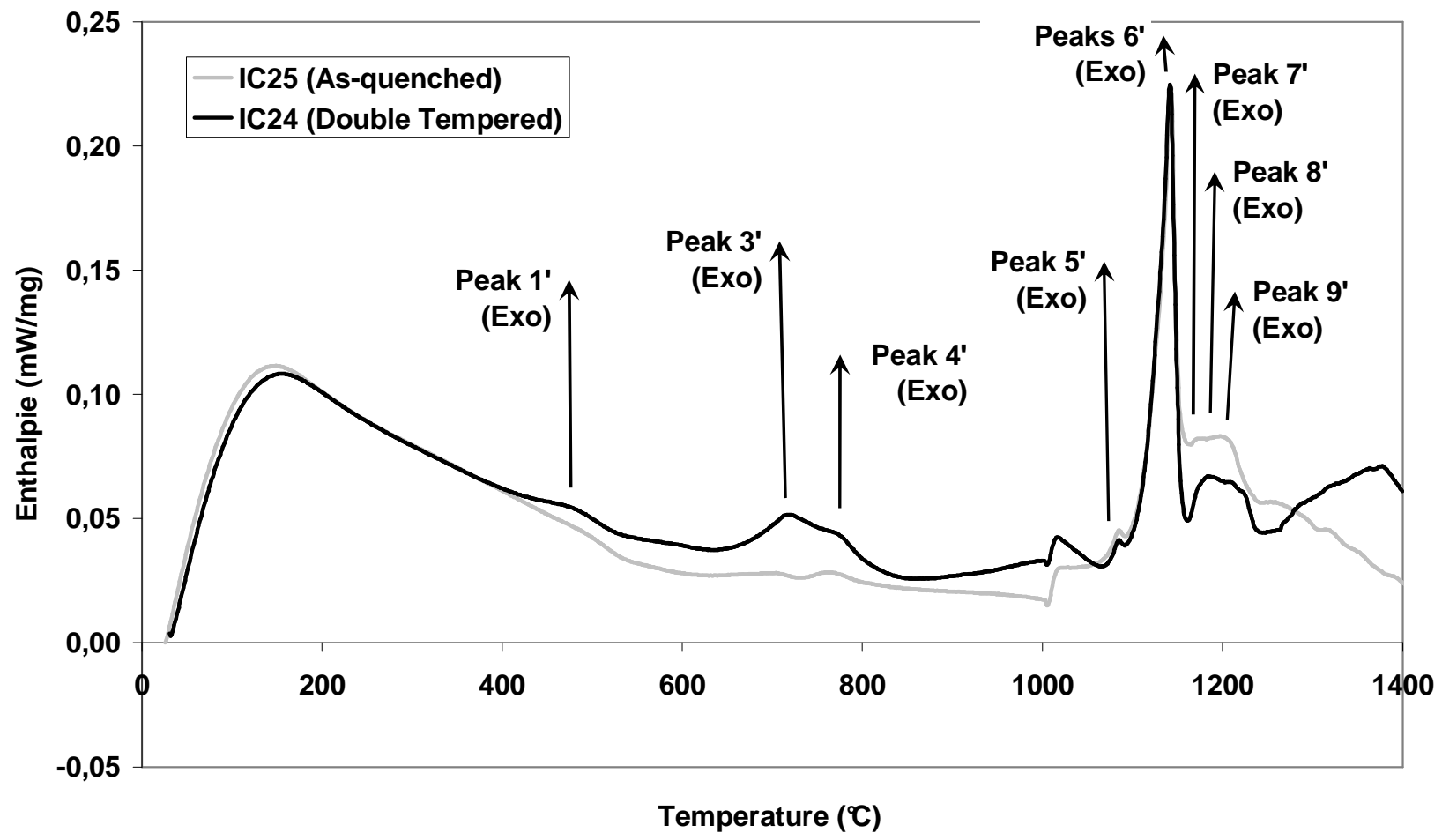




\section{Crystallization behavior towards DTA cooling mode}

Solidification sequence as determined during the DTA cooling mode was quite similar for both IC1 and IC2 grades, except for the primary NbC precipitation at the beginning of the solidification process (peak 9), and the martensitic transformations appearing close to the room temperature (peaks 1 and 1bis). Indeed peak 1bis amplitude was lower on IC1 series (Fig. 2a) than that of IC2 (fig 2b).

Peak 1bis that is more clearly enhanced on IC2 series than IC1, was reported to be related to a reaction quite similar to that of peak 1 , namely martensitic transformation from a retained austenitic phase at the end of the cooling stage of the DTA test. Such a differentiation between peak 1 and peak 1 bis suggested that martensitic phases that are linked to these peaks could be of different types. The DTA cooling mode yields a reduced number of peaks, when compared to the DTA heating mode. Indeed, only 5 and 6 peaks were respectively observed on IC1 and IC2 series at the end of the DTA cooling stage whereas as 8 to 9 peaks were found during the DTA heating stage.

Table 3: Signification of DTA peaks and related phase transformations during heating mode, on IC1 and IC2 series.

\begin{tabular}{|c|c|c|c|c|c|c|}
\hline \multirow{2}{*}{$\begin{array}{c}\text { Peaks } \\
\text { number }\end{array}$} & \multirow{2}{*}{$\begin{array}{c}\text { Phase transformation } \\
\text { reactions }\end{array}$} & \multirow{2}{*}{$\begin{array}{c}\text { Phase transformation } \\
\text { designations }\end{array}$} & \multicolumn{4}{|c|}{ Peaks occurrence } \\
\hline & & & IC12 & IC13 & IC24 & IC25 \\
\hline 1 ' & $\alpha^{\prime} \rightarrow \gamma_{1}$ & $\begin{array}{l}\text { Direct transformation of } \\
\text { martensite into austenite }\end{array}$ & \multicolumn{2}{|c|}{ No } & \multicolumn{2}{|c|}{ Yes } \\
\hline 2 & $\alpha^{\prime} \rightarrow \alpha "+\eta$ & $\begin{array}{l}\text { Tempering of martensite and fine } \\
\text { carbides precipitation }\end{array}$ & \multicolumn{2}{|c|}{ Yes } & \multicolumn{2}{|c|}{ No } \\
\hline 3 & $\alpha " \rightarrow \gamma_{2}$ & $\begin{array}{c}\text { Reverse eutectoid } 1 \text { (tempered } \\
\text { martensite transformed into } \\
\text { austenite }\end{array}$ & Yes & No & & \\
\hline 4 & $\mathrm{M}_{4} \mathrm{C}_{3}+\gamma_{2}, \rightarrow \gamma_{3}$ & $\begin{array}{c}\text { Reverse eutectoid } 2 \text { (Fine } \\
\text { secondary carbides dissolution) }\end{array}$ & \multicolumn{2}{|c|}{ No } & \multicolumn{2}{|c|}{ Yes } \\
\hline 5 & $(\mathrm{Nb}, \mathrm{V}) \mathrm{C}^{\prime}+\gamma_{4} \rightarrow \mathrm{L}_{1}$ & $\begin{array}{c}\text { Reverse eutectic } 1(\text { direct melting } \\
\text { of eutectic }(\mathrm{Nb}, \mathrm{V}) \mathrm{C})\end{array}$ & \multicolumn{2}{|c|}{ No } & \multicolumn{2}{|c|}{ Yes } \\
\hline 6 & $\mathrm{M}_{3} \mathrm{C}+\gamma_{5} \rightarrow \mathrm{L}_{2}$ & $\begin{array}{c}\text { Reverse eutectic } 2 \text { (direct melting } \\
\text { of ledeburite) }\end{array}$ & \multicolumn{2}{|c|}{ Yes } & \multicolumn{2}{|c|}{ Yes } \\
\hline $7^{\prime}$ & $\mathrm{C}_{\mathrm{A}}\left(+\gamma_{6}\right) \rightarrow \mathrm{L}_{3}$ & Direct melting of Graphite type A & \multicolumn{2}{|c|}{ Yes } & \multicolumn{2}{|c|}{ Yes } \\
\hline 8 & $\mathrm{C}_{\mathrm{D}}+\left(\gamma_{7}\right) \rightarrow \mathrm{L}_{4}$ & Direct melting of Graphite type D & \multicolumn{2}{|c|}{ Yes } & \multicolumn{2}{|c|}{ Yes } \\
\hline 9' & $\mathrm{NbC} \rightarrow \mathrm{L}_{5}$ & Direct melting of primary $\mathrm{NbC}$ & \multicolumn{2}{|c|}{ No } & \multicolumn{2}{|c|}{ Yes } \\
\hline
\end{tabular}

\section{Microstructure characterization}

The observation of re-solidified samples at the end of DTA tests led to set the sequence of phase precipitations within the cross section of the given sample, since solidification started close to the sample surface and ended in the centre of the sample (see fig. 3a to $3 \mathrm{f}$, for IC1 series and fig. 4a to 4f, for IC2 series). Indeed, cubic MC carbides were found near the surface of IC2 re-solidified samples (fig. 4a, 4f), owing the fact that such carbides precipitated at the beginning of the solidification process.

Another type of MC namely Chinese script shaped $\mathrm{NbC}$, was found in the core of the re-solidified sample (fig. 4c). Thus, it had been assumed that bulky cubic MC precipitated first, and Chinese script $\mathrm{NbC}$ precipated latter, the former type being promoting by higher cooling rates occurring near the surface. 
Fig. 2a: DTA curves on IC12 and IC13 (Cooling mode at $5^{\circ} \mathrm{C} / \mathrm{min}$, from melt down to room $\mathrm{T}^{\circ}$ )

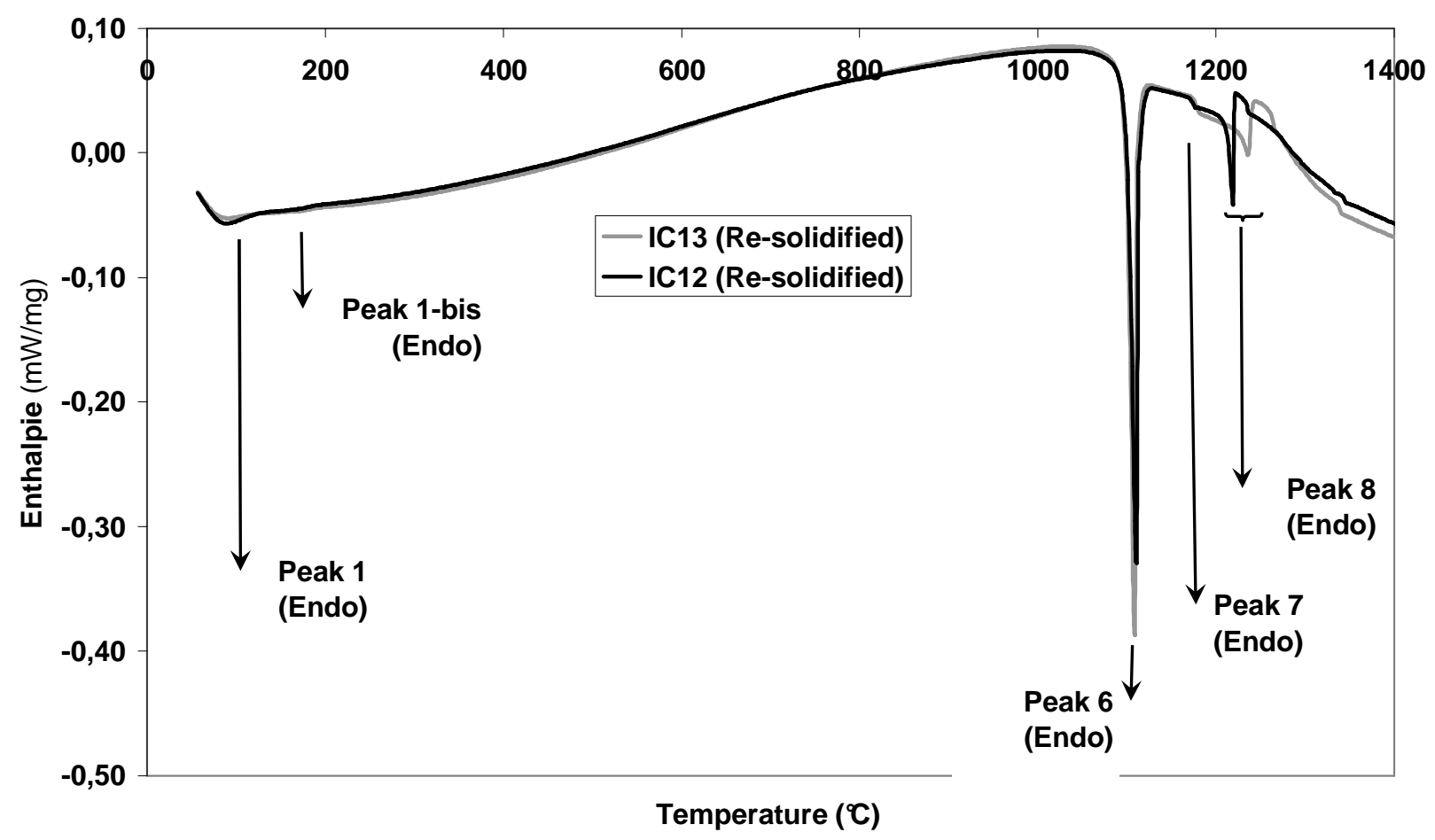

Fig. 2B: DTA curves on IC24 and IC25 (Cooling mode at $5^{\circ} \mathrm{C} / \mathrm{min}$, from melt down to room $\mathrm{T}^{\circ}$ )

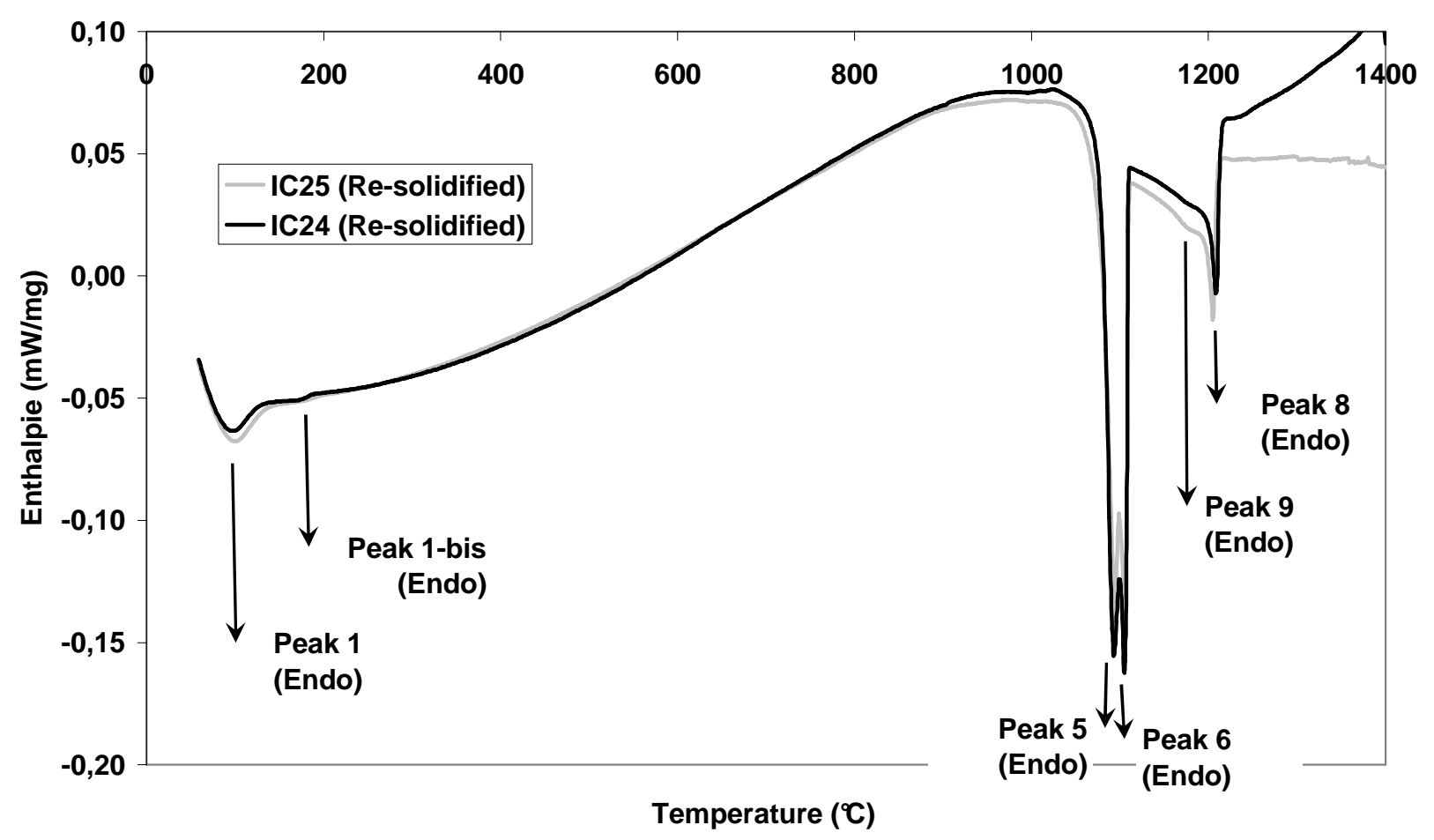


Similar observations could be made regarding graphite morphology. Indeed two types of graphite were found in both re-solidified IC1 and IC2 series, namely type A and type D, the latter being finer in size than the former (fig. 3a to 3d). Type D graphite appeared to form firstly, as it was located near the surface (fig. 3a, 4a) whereas type A which is more flaky, is located deeper inside the resolidified sample (fig. 3d, 4a, 4c).

Quenching seemed to have less influence on phase transformations on IC2 series than IC1 series. Alloying elements that are dissolved in IC2 series austenite during quenching tended to inhibit martensite transformation into austenite, during re-heating, as it was the case with IC1 series.

By failing to recover all the peaks related to phase transformations that occurred at the time of the casting process, DTA tests enhance the difficulty which exists when simulations are carried out in order to reproduce the actual solidification route of complex alloys such as HACI. Indeed, the industrial spin casting process involved various cooling rates together with fluid dynamics phenomenon, as the melt is submitted to a significant rotation.

However, certain reactions could be studied and were found to be little influenced by alloying elements additions as ledeburite and graphite exhibited similar ranges on both IC1 and IC2 series.

Table 4: Signification of DTA peaks and related phase transformations during cooling mode, on IC1 and IC2 series.

\begin{tabular}{|c|c|c|c|c|}
\hline \multirow{2}{*}{$\begin{array}{l}\text { Peaks } \\
\text { number }\end{array}$} & \multirow{2}{*}{$\begin{array}{c}\text { Phase transformation } \\
\text { reactions }\end{array}$} & \multirow{2}{*}{$\begin{array}{c}\begin{array}{c}\text { Phase transformation } \\
\text { designations }\end{array} \\
\end{array}$} & \multicolumn{2}{|c|}{ Peaks occurrence } \\
\hline & & & \begin{tabular}{|l|l|} 
IC12 & IC13 \\
\end{tabular} & \begin{tabular}{l|l} 
IC24 & IC25 \\
\end{tabular} \\
\hline 9' & $\mathrm{L}_{1} \rightarrow \mathrm{NbC}$ & $\begin{array}{l}\text { Direct precipitation of tetragonal } \\
\text { primary } \mathrm{NbC}\end{array}$ & No & Yes \\
\hline $8^{\prime}$ & $\mathrm{L}_{0} \rightarrow \mathrm{C}_{\mathrm{D}}+\left(\gamma_{1}\right)$ & $\begin{array}{c}\text { Direct precipitation of Graphite } \\
\text { type D }\end{array}$ & Yes & Yes \\
\hline 7 & $\mathrm{~L}_{2} \rightarrow \mathrm{C}_{\mathrm{A}}\left(+\gamma_{2}\right)$ & $\begin{array}{c}\text { Direct precipitation of Graphite } \\
\text { type A }\end{array}$ & Yes & No \\
\hline $6{ }^{\prime}$ & $\mathrm{L}_{3} \rightarrow \mathrm{M}_{3} \mathrm{C}+\gamma_{3}$ & $\begin{array}{l}\text { Eutectic } 1 \text { (Formation of } \\
\text { Ledeburite from the melt) }\end{array}$ & Yes & Yes \\
\hline $5^{\prime}$ & $\mathrm{L}_{4} \rightarrow(\mathrm{Nb}, \mathrm{V}) \mathrm{C}^{\prime}+\gamma_{4}$ & $\begin{array}{l}\text { Eutectic } 2 \text { (precipitation of } \\
\text { Chinese script }(\mathrm{Nb}, \mathrm{V}) \mathrm{C})\end{array}$ & No & Yes \\
\hline 1bis' & $\gamma_{6} \rightarrow \alpha_{2}^{\prime}$ & $\begin{array}{c}\text { Martensitic transformation } \\
\text { (Lath type) }\end{array}$ & Yes & Yes \\
\hline $1 '$ & $\gamma_{5} \rightarrow \alpha^{\prime}{ }_{1}$ & $\begin{array}{c}\text { Martensitic transformation } \\
\text { (Plate type) }\end{array}$ & Yes & Yes \\
\hline
\end{tabular}


Fig. 3a: Graphite Type D (dark) close to the surface on IC12 re-solidified after DTA test; as-polished with Polarized Light (Crossed Nichols)

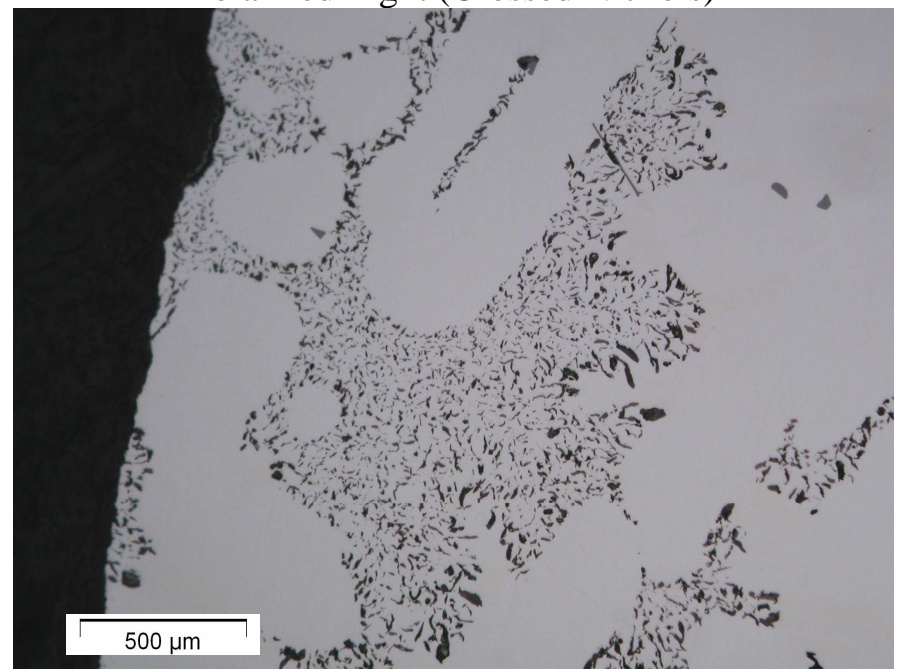

Fig. 3c: Graphite Type D (dark), Cementite (light), and matrix on IC12 re-solidified; Nital etched

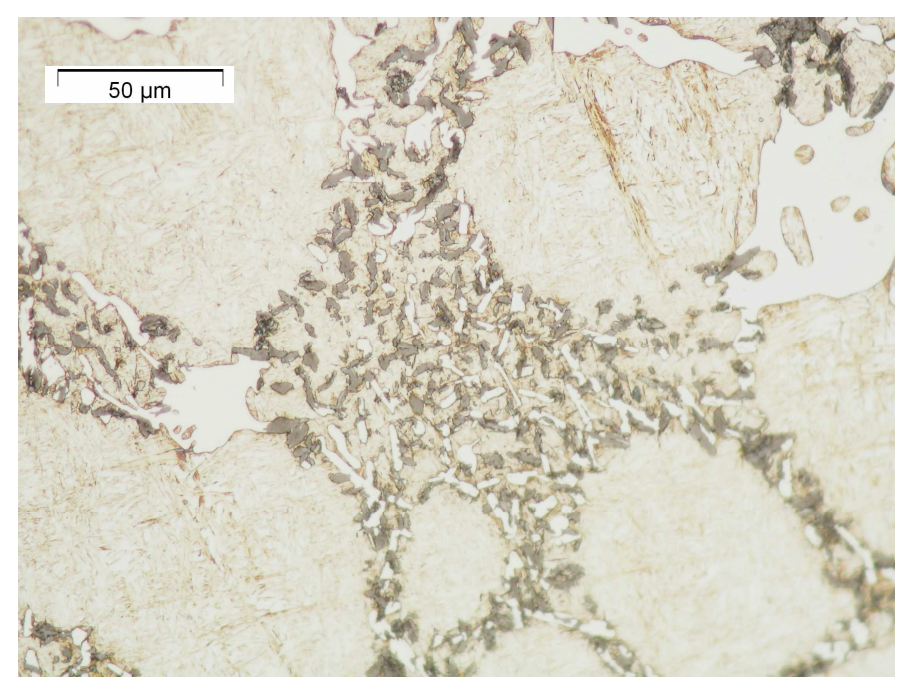

Fig. 3e: Ledeburite (light to grey) towards Crossed Nichols on IC13 re-solidified; as-polished (polarized light)

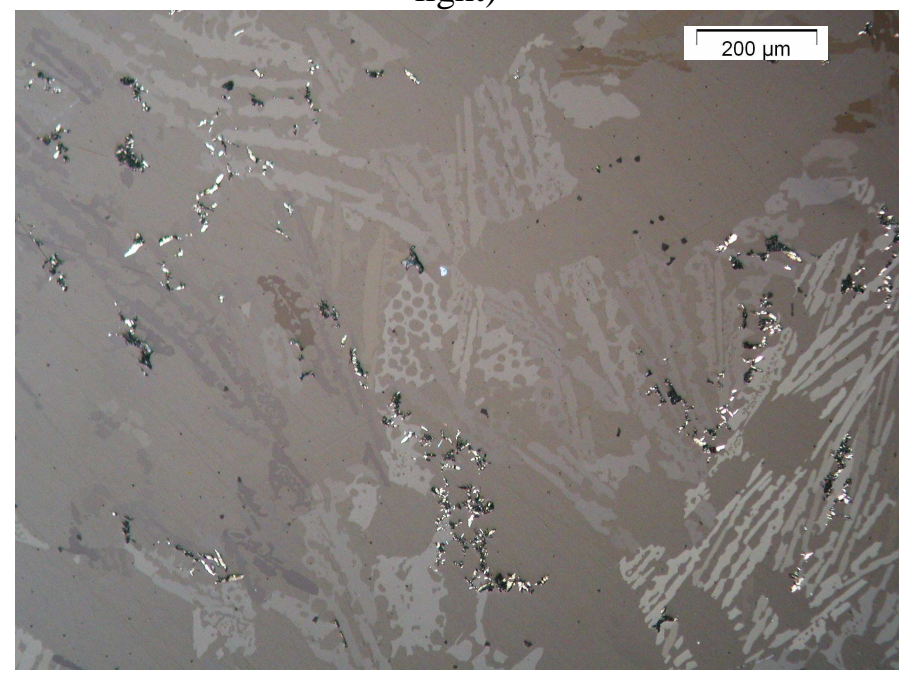

Fig. 3b: Graphite Type D (dark) close to the surface and Cementite (light) on IC12 re-solidified after DTA test; Nital etched

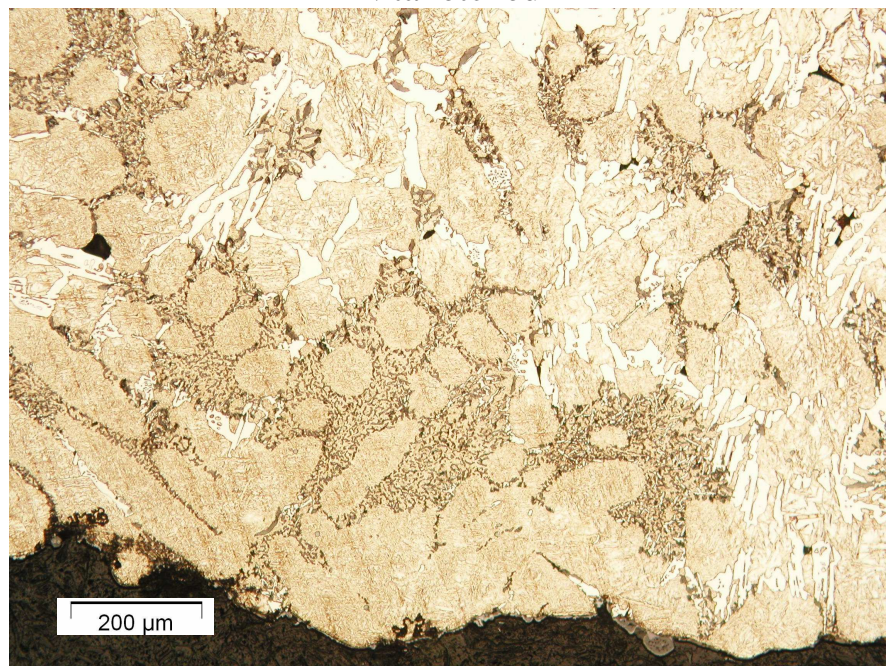

Fig. 3d: Graphite Type A (dark) with surrounding

Cementite (light) and mixed matrix on IC12 re-solidified after DTA test; Nital etched

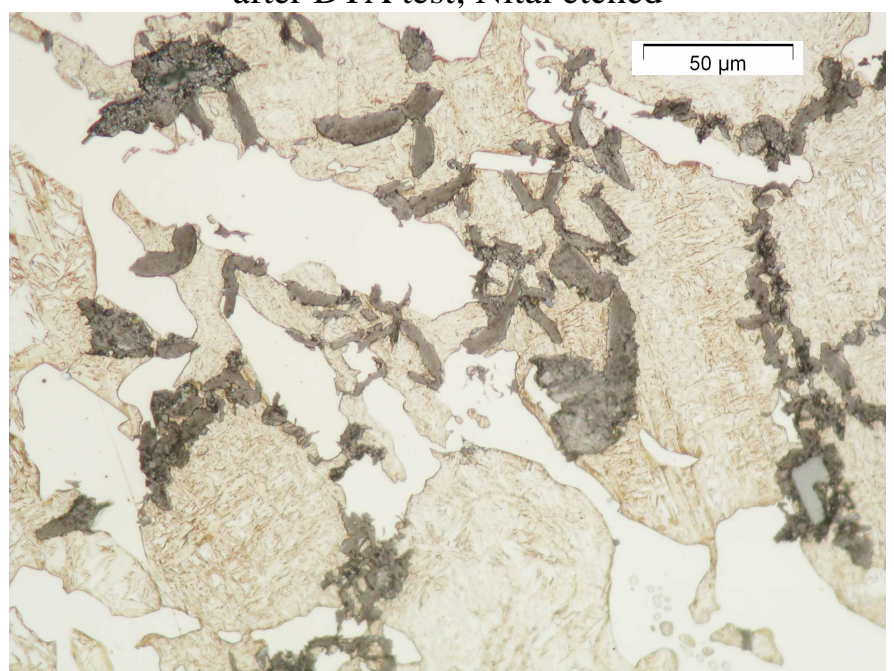

Fig. 3f: Plate Martensite (needles) and retained austenite (light), in the vicinity of Cementite; IC12 re-solidified after DTA test (Nital etched)

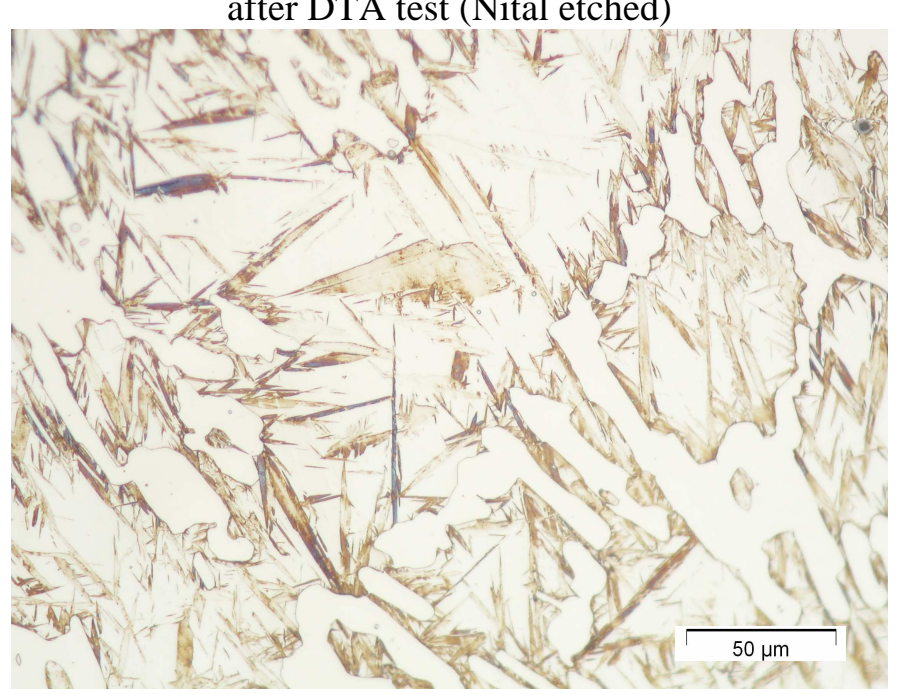


Fig. 4a: Primary tetragonal NbC (Pink) near the surface and Graphite Type D (dark) deep inside de sample; IC25

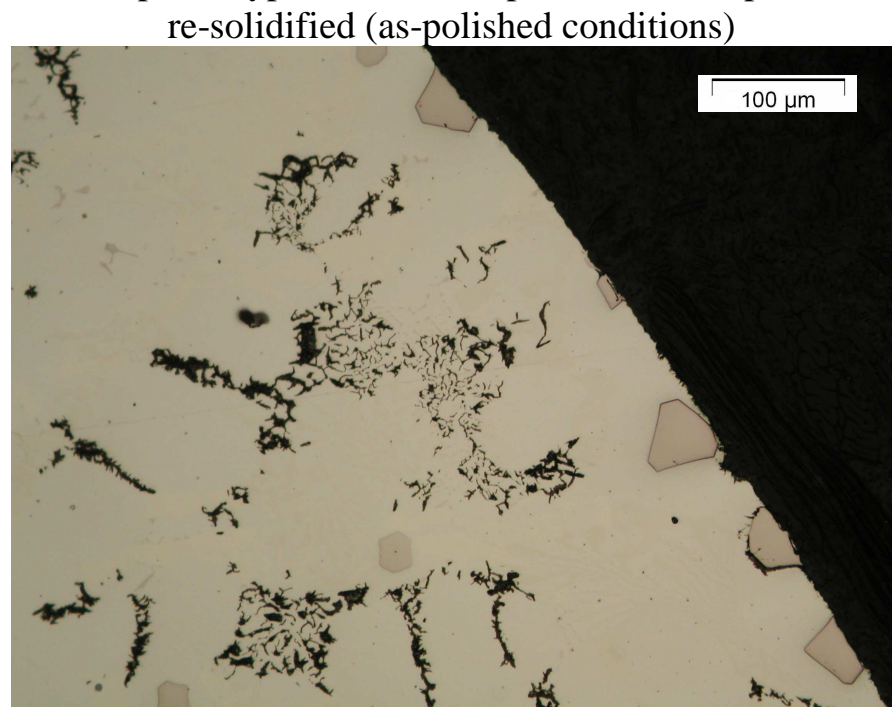

Fig. 4c: Tetragonal Primary $\mathrm{NbC}$ (near the surface) and

Chinese Script eutectic $(\mathrm{Nb}, \mathrm{V}) \mathrm{C}^{\prime}$ (inside) in IC24 re-

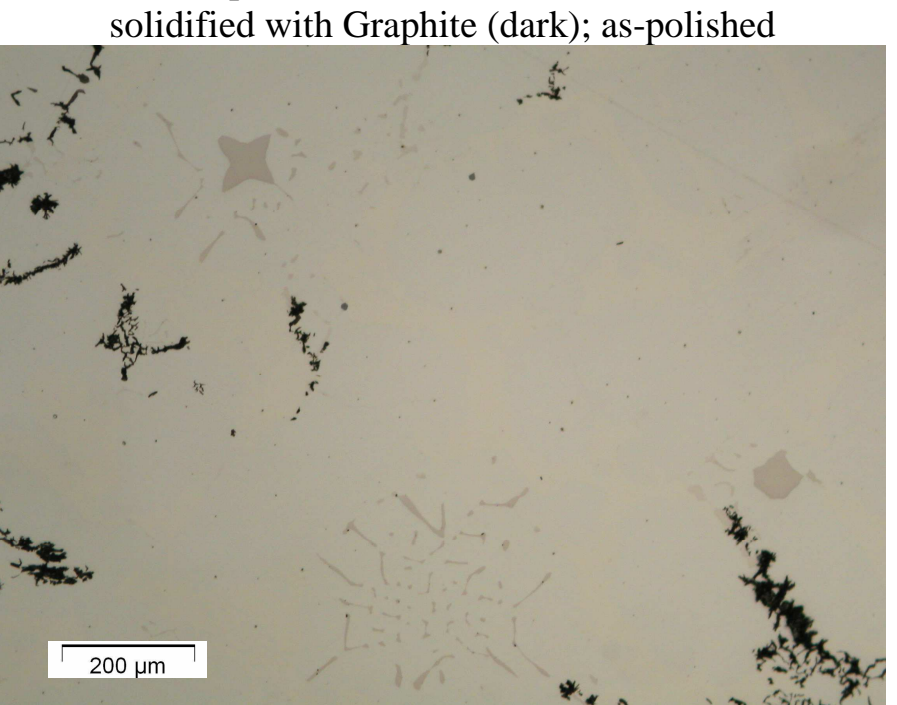

Fig. 4e: Plate Martensite (type 1, larges needles) and retained austenite (light) with surrounding ledeburite; IC24 re-solidified (Nital etched)

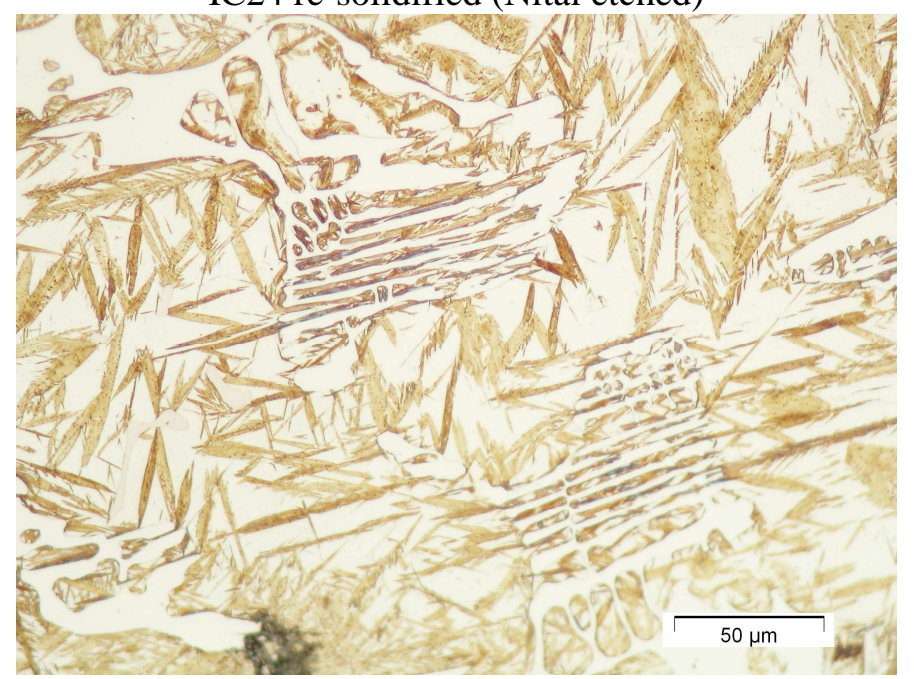

Fig. 4b: Tetragonal primary NbC surrounded by Graphite Type D; IC24 re-solidified after DTA test (as-polished)

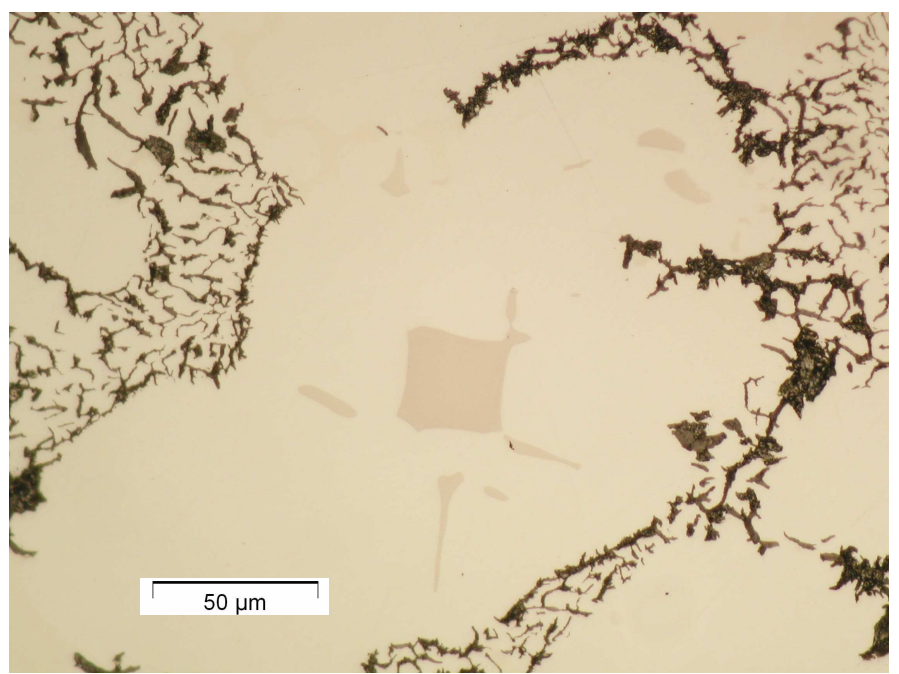

Fig. 4d: Ledeburite surrounded by a mixed matrix of martensite and retained austenite; IC24 re-solidified

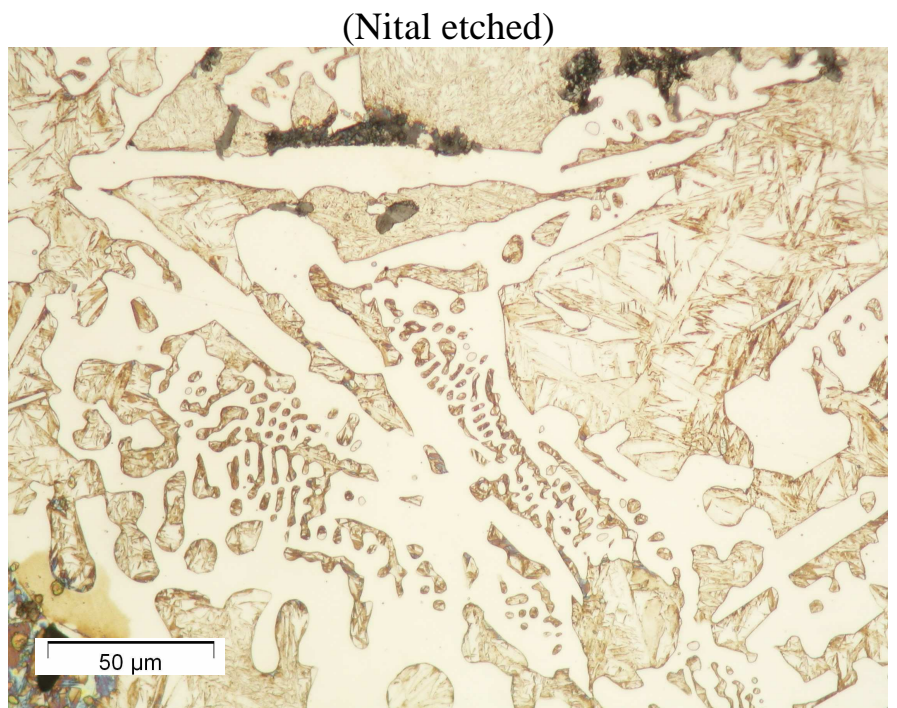

Fig. 4f: Lath martensite (type 2) near the surface and in the vicinity of both graphite and $\mathrm{NbC}$ primary carbides; IC24 re-solidified (Nital Etched)

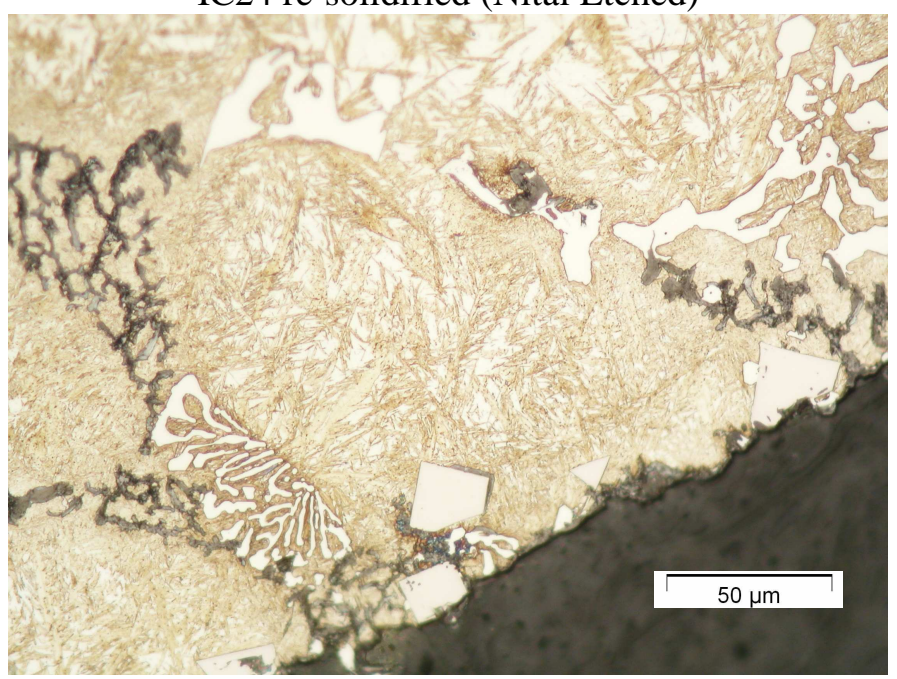




\section{Phase volumes fractions}

Quantification of phases was carried out towards images analysis. Results are given in Table 5.

Table 5: Average volume fraction of various phases found on studied samples (\%)

\begin{tabular}{|c|c|c|c|}
\hline Samples & IC11 & IC21 & IC22 \\
\hline Phases & - & $0.2-1.7$ & $1.0-1.5$ \\
\hline GbC & $2.3-4.2$ & $2.5-3.4$ & $3.0-3.5$ \\
\hline $\mathrm{M}_{3} \mathrm{C}$ & $34-45$ & $28-38$ & $25-40$ \\
\hline Martensite & $52-62$ & $58-68$ & $55-70$ \\
\hline
\end{tabular}

IC2 series exhibit an improved amount of martensite, when compared to IC1 series, with a related reduced volume fraction of Cementite. Graphite amount remained similar in both grades.

\section{Discussion and conclusion}

Differential Thermal Analysis (DTA) was carried out on the heat treated samples in order to determine the phase transformations occurring during re-heating to the melt on the one hand, and to determine the crystallization behavior from the solidification sequence on the other hand.

Two types of MC carbides were found on IC2 series. Firstly was the tetragonal bulky MC, often located near the surface of re-solidified samples. Then finer Chinese script MC carbides were found deep inside de sample, at the end of DTA test.

Then it could be assumed that higher solidification rates promoted tetragonal $\mathrm{MC}$ whereas as lower solidification rate gave rise to finer MC.

Two types of graphite were also found on both IC alloys, namely types A and D [16, 17].

The type D seemed to be more numerous than graphite A, on re-solidified samples IC2 specimens. Such a higher graphite D content suggested that this type of graphite is promoted by higher solidification rates [4].

Two types of martensite were found in both IC1 and IC2 series, namely conventional plate martensite and additional lath-like martensite [1]. Each type of martensite is being linked to a specific peak at the time of DTA cooling stage. Moreover, lath martensite appeared to be located in the vicinity of either bulky $\mathrm{NbC}$ or graphite clusters, whereas plate martensite was found close to ledeburite areas.

The occurrence of a double peak, namely peak 1 and peak 1bis suggested that the two martensitic phases, from which they originated from, could probably be differentiated through their alloying elements content $[1,22]$. Indeed a major differentiation was observed on the morphology of theses two martensite phases, as the first one located near tetragonal $\mathrm{NbC}$ and the graphite cluster was finer than the plate-like martensite found in the vicinity of ledeburite.

$\mathrm{Nb}, \mathrm{V}$ and $\mathrm{Ti}$ additions appeared to:

- lower the melting point of HACI grade

- enhance the secondary carbides precipitation at the time of tempering

- promote the formation of a lath martensite in addition to the plate martensite type, the former being located in the vicinity of bulky primary $\mathrm{NbC}$ and graphite clusters

The overall phase volume fractions was hardly modified with $\mathrm{Nb} / \mathrm{Ti} / \mathrm{v}$ addition, as there was a slight increase of martensite together with a slight decrease of both cementite and graphite.

Finally it was suggested that martensite could also be destabilized during the re-heating stage, to form a more stable austenite. 


\section{Acknowledgements}

The authors wish to express their thankfulness of the financial support by Walloon Region, and MK group for their continuous interest on this research and the material supply.

\section{References}

[1] M. Durand-Charre: La microstructure des aciers et des fontes (Genèse et interprétation) (Ed. Sirpe, 2003)

[2] J. Tchoufang Tchuindjang and J. Lecomte-Beckers: Inter. Jr. Fat. Vol. 29 (2007), p. 713

[3] H-Q. Wu, N. Sasaguri, Y. Matsubara: Abrasion 2002, Proceedings, Fukuoka (Japan), p. 167

[4] T. G. Oakwood, G. M. Goodrich, R. B. Gundlach: AFS Transactions, Vol. 02-031, (2002), p. 1

[5] T. Nylen: Niobium 2001, Proceedings, Orlando (USA), p. 1063

[6] Y. Matsubara, N. Sasaguri, K. Shimizu and S. K. Yu: Wear Vol. 250 (2001), p. 502

[7] Y-H. Shy, C-H. Hsu, S-C. Lee, C-Y. Hou: Mater. Sci. Eng. A Vol. 278 (2000), p. 54

[8] S.K. Hann and J. D. Gates: Jr. of Mater. Sci. Vol. 32 (1997), p. 1249

[9] Y. Uematsu, K. Tokaji, T. Horie and K. Nishikagi: Mater. Sci. Eng. A Vol. 471 (2007), p. 15

[10] J. Tchoufang Tchuindjang, L. Terziev, M. Sinnaeve, G. Mukadi Kantabilenga, J. LecomteBeckers: SBM 2007, Annual Meeting, Proceedings, Liege (Belgium)

[11]H. Liu, J. Wang, H. Yang and B. Shen: Mater. Sci. Eng. A Vol. 478 (2008), p. 324

[12] N. Luzginova, L. Zhao, J. Sietsma: Mater. Sci. Eng. A Vol. 448 (2007), p. 104

[13] G. Zajac and J. Pacyna: Jr. of Mater. Proc. Techno. Vol. 162-163 (2005), p. 442

[14] A. R. Ghaderi, M. Nili Ahmadabadi and H. M. Ghasemi: Wear Vol. 255 (2003), p. 410

[15]L. A. Dobrzanski, A. Zarychta and M. Ligarski: Jr. of Mater. Proc. Techno. Vol. 63 (1997), p. 531

[16]D. D. Double and A. Hellawell: Acta; Metall; Mater. Vol. 43 (1995), p. 2435

[17] G. F. Geier, W. Bauer, B. J. McKay and P. Schumacher: Mater. Sci. Eng. A Vol. 413-414 (2005), p. 339

[18] R. Källbom, K. Hamberg, M. Wessen and L.-E. Björkegren: Mater. Sci. Eng. A Vol. 413-414 (2005), p. 346

[19] K. Edalati, F. Akhlaghi, M. Nili-Ahmadabadi: Jr. of Mater. Proc. Techno. Vol. 160 (2005), p. 183

[20] C. G. Schön and A. Sinatora: Calphad Vol. 22, No 4 (1999), p. 437

[21] J. Lecomte-Beckers and J. Tchoufang Tchuindjang: EMAC 2004, Proceedings, Antwerp (Belgium)

[22]H. K. D. H. Bhadeshia: Metal Science Vol. 17 (1983), p. 151 